\title{
A solid-contact $\mathrm{Pb}^{2+}$-selective electrode using poly(2-methoxy-5- (2'-ethylhexyloxy)-p-phenylene vinylene) as ion-to-electron transducer
}

\author{
Shunyang Yu ${ }^{a}$, Fuhai Li ${ }^{\mathrm{a}, \mathrm{b}}$, Tanji Yin ${ }^{\mathrm{a}}$, Yongming Liu ${ }^{\mathrm{b}}$, Dawei Pan ${ }^{\mathrm{a}}$, Wei Qin ${ }^{\mathrm{a}, *}$ \\ ${ }^{a}$ CAS and Shandong Provincial Key Laboratory of Coastal Zone Environmental Processes, Yantai Institute of Coastal Zone Research, Chinese Academy of Sciences, \\ Yantai 264003, PR China \\ ${ }^{\mathrm{b}}$ Chemistry and Chemical Engineering College, Yantai University, Yantai 264005, PR China
}

\section{A R T I C L E I N F O}

\section{Article history:}

Received 4 May 2011

Received in revised form 22 June 2011

Accepted 26 June 2011

Available online 5 July 2011

\section{Keywords:}

Ion-selective electrodes

Solid contact

Low detection limit

Conducting polymer

\begin{abstract}
A B S T R A C T
In this work, a novel all-solid-state polymeric membrane $\mathrm{Pb}^{2+}$-selective electrode was developed by using for the first time poly(2-methoxy-5-(2'-ethylhexyloxy)-p-phenylene vinylene) (MEH-PPV) as solid contact. To demonstrate the ion-to-electron transducing ability of MEH-PPV, chronopotentiometry and electrochemical impedance spectroscopy measurements were carried out. The proposed electrodes showed a Nernstian response of $29.1 \mathrm{mV}$ decade $^{-1}$ and a lower detection limit of subnanomolar level. No water film was observed with the conventional plasticized PVC membrane. This work demonstrates a new strategy for the fabrication of robust potentiometric ion sensors.
\end{abstract}

(c) 2011 Elsevier B.V. All rights reserved.

\section{Introduction}

In recent years, solid-contact ion-selective electrodes (SC-ISEs) have been envisioned as a viable alternative to the conventional electrodes with inner solution arrangement in view of their promise in robust system, free maintenance, and miniaturization [1,2]. As a key component, the solid contact plays a critical role in the electrode characteristics, such as linear response range, selectivity and potential stability in particular [3-5]. Until now, many kinds of materials, including redox-active monolayers [6], carbon materials [7-11], and conducting polymers (CPs) [12] have been introduced between the conducting substrates and the ion-selective membranes to obtain thermodynamically defined electrochemical interfaces.

Due to their commercially availability, ease of processing and fast electrochemical switching, CPs have gain more interests in practice. CPs represent a large family of synthetic metals, however, the commonly studied subjects of SC-ISEs were mostly confined to polypyrrole [13-15], polyaniline [16,17], polythiophene, and their derivatives [18-20]. From both the experimental and theoretical points of view, it is of great significance to provide new solid contact materials for fabricating SC-ISEs. To obtain a SC-ISE with satisfactory performance, three requirements must be met for the inner

\footnotetext{
* Corresponding author. Tel.: +86 535 2109156; fax: +86 5352109000.

E-mail address: wqin@yic.ac.cn (W. Qin).
}

contact including high chemical stability, proper ion to electron transduction and good adhesion with matrix polymer. It has been reported that the buildup of well-defined interface through the selection of the conductive polymer films does not necessarily lead to good performances of SC-ISEs [21], however, a thin aqueous layer formed between the ion-selective membrane and the conducting polymer could account for the potential drifts and poor detection limits of the electrodes [22,23]. Recently, a novel approach was developed for the production of analytically robust sensors by the use of an acrylate copolymer (P(MMA-DMA)) as the ion-selective membrane matrix, and poly(3-octylthiophene)(POT) solid contact as the ion-to-electron transducer $[1,19,23,24]$. The diffusion coefficients in $\mathrm{P}(\mathrm{MMA}-\mathrm{DMA})$ copolymer $\left(\sim 10^{-11} \mathrm{~cm}^{2} \mathrm{~s}^{-1}\right)$ are up to three orders of magnitude lower than those for conventional plasticize PVC membranes [25], which may make it relatively robust to chemical changes at the inner membrane side. The drawback of this copolymer is that it is currently synthesized in-house. From the practical viewpoint, there is still a great need for the fabrication of SC-ISEs by using commercially available polymer matrixes [13].

In this article, we demonstrate that the use of poly(2-methoxy5-(2'-ethylhexyloxy)-p-phenylene vinylene) (MEH-PPV) as active ion-to-electron transducer along with conventional plasticized PVC sensing membrane is an excellent strategy for avoiding the detrimental water layer formed at the buried interface of SC-ISEs. The performance of the new inner contact material and the response characteristics of the polymeric membrane electrode will be presented. 


\section{Experimental}

\subsection{Reagents}

Poly(vinyl chloride) (PVC), poly(2-methoxy-5-(2'-ethylhexyloxy)-p-phenylene vinylene)(MEH-PPV), 2-nitrophenyl octyl ether (o-NPOE), sodium tetrakis[3,5-bis(trifluoromethyl)phenyl]borate (NaTFPB), and the lead ionophore, tert-butylcalix[4]arenetetrakis(N,N-dimethylthioacetamide) were purchased from Sigma-Aldrich. All other reagents used were purchased from Sinopharm Chemical Reagent and of analytical grade purity or better. Deionized water with specific resistance of $18.2 \mathrm{M} \mathrm{cm}$ was obtained by a Pall Cascada Laboratory Water System.

\subsection{Ion-selective membranes and electrodes}

The ion selective membrane contained $35 \mathrm{wt} \%$ PVC, $63 \mathrm{wt} \%$ oNPOE, $1.4 \mathrm{wt} \%$ lead ionophore, and $0.6 \mathrm{wt} \%$ NaTFPB. A total of $250 \mathrm{mg}$ of the membrane components was dissolved in $2.0 \mathrm{~mL}$ of THF. Polished and well-rinsed Au disk electrodes with an area of $0.07 \mathrm{~cm}^{2}$ were used as conducting substrates for SC-ISEs. For preparation of each solid-contact electrode, $10-20 \mu \mathrm{L}$ of a $50 \mathrm{mg} \mathrm{mL}^{-1}$ MEH-PPV solution in chlorobenzene was applied on the Au disc by drop-casting. After the CP membrane was dry, a piece of PVC tube was put on the tip of the Au disc electrode [1,13]. Finally, $100 \mu \mathrm{L}$ of membrane cocktail was cast on the top of CP surrounded by the PVC tube. $\mathrm{Pb}^{2+}$-selective coated-disk electrodes (CDEs) were also prepared by directly pipetting the membrane cocktail onto the bare Au disk electrodes.

\subsection{Potentiometric measurements}

Membrane potentials were measured with a Model PXSJ-216 digital ion analyzer (Shanghai Leici Instruments Factory, China) in magnetically stirred solution at room temperature in the galvanic cell. $\mathrm{Hg} / \mathrm{Hg}_{2} \mathrm{Cl}_{2}$ with double junction was used as reference electrode with $1 \mathrm{M} \mathrm{LiOAc}$ as salt bridge electrolyte. Activity coefficients were calculated according to the Debye-Hückel approximation and electromotive force(EMF) values were corrected for liquid-junction potentials with the Henderson equation. For the measurements in dilute solutions, the electrodes were conditioned in $10^{-3} \mathrm{M}$ $\mathrm{Pb}\left(\mathrm{NO}_{3}\right)_{2}$ overnight and then in $10^{-9} \mathrm{M} \mathrm{Pb}\left(\mathrm{NO}_{3}\right)_{2}$ solution for 2 days. All $\mathrm{Pb}\left(\mathrm{NO}_{3}\right)_{2}$ sample solutions had the same background of $10^{-3} \mathrm{M} \mathrm{NaNO}_{3}$. Calibration was performed from higher to lower activities.

\subsection{Chronopotentiometry}

Chronopotentiometric studies were carried out on the fabricated solid-contact $\mathrm{Pb}^{2+}$-ISEs in $0.1 \mathrm{M} \mathrm{Pb}\left(\mathrm{NO}_{3}\right)_{2}$ solution by applying a constant current of $+1 \mathrm{nA}$ for $60 \mathrm{~s}$ followed by $-1 \mathrm{nA}$ for another $60 \mathrm{~s}$ while the potential of the electrodes was recorded as a function of time. The measurements were performed using CHI 660C Electrochemical Workstation (Shanghai Chenhua Instruments Company, China) with an $\mathrm{Ag} / \mathrm{AgCl} / 3 \mathrm{M} \mathrm{KCl}$ as reference electrode.

\subsection{Electrochemical impedance spectroscopy measurements}

Electrochemical impedance spectroscopy (EIS) measurements were performed in deaerated $0.1 \mathrm{M} \mathrm{Pb}\left(\mathrm{NO}_{3}\right)_{2}$ solution by using $\mathrm{CHI}$ 660C Electrochemical Workstation with an $\mathrm{Ag} / \mathrm{AgCl} / 3 \mathrm{M} \mathrm{KCl}$ and platinum as reference and counter electrodes, respectively. EIS data were recorded at open circuit potential with an AC amplitude of $100 \mathrm{mV}$ and a frequency range of $200 \mathrm{kHz}$ to $1 \mathrm{MHz}$.

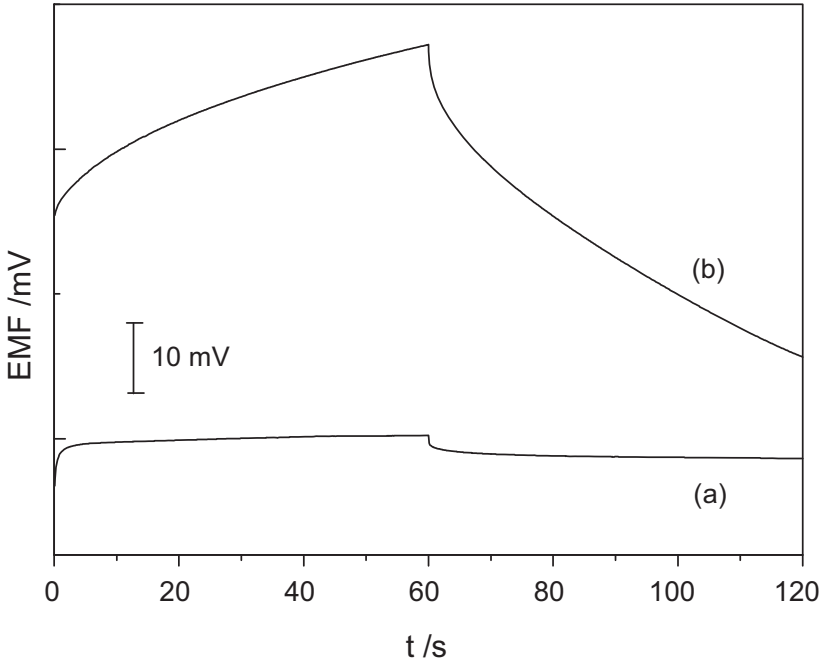

Fig. 1. Chronopotentiograms recorded for the $\mathrm{Pb}^{2+}$-selective electrodes: (a) $\mathrm{Au} / \mathrm{MEH}-\mathrm{PPV} / \mathrm{Pb}^{2+}$-selective membrane and (b) $\mathrm{Au} / \mathrm{Pb}^{2+}$-selective membrane (CDE)

\section{Results and discussion}

\subsection{Chronopotentiometric studies}

Due to its stability, processability, and electrical and optical properties, MEH-PPV has been considered for a wide variety of electronic applications [26]. A key characteristic of any material intended as the solid contact for ISEs is its capacitance, $C$. The electrode potential stability can be improved by the use of an inner contact with sufficiently high capacitance. To evaluate the capacitance of the fabricated electrode, chronopotentiometry was carried out in $0.1 \mathrm{M} \mathrm{Pb}\left(\mathrm{NO}_{3}\right)_{2}$ solution and the current applied was equal to $1 \mathrm{nA}$. The chronopotentiograms are illustrated in Fig. 1. According to the slope of the linear part of the $E$ vs. time dependence curve which directly relates to the low frequency capacitance of the system, $\mathrm{d} E / \mathrm{d} t=i / C$, the capacitance thus obtained for MEH-PPVbased electrode is $30 \mu \mathrm{F}$, which is one order of magnitude higher than the typical capacitance of CDE arrangement [27]. Moreover, the potential jump when changing the direction of the current in the $E$ - $t$ curves can be used to estimate the total resistance $(R)$ of the electrode which is dominated by the bulk resistance of the plasticized PVC-based membrane. According to Ohm's law: $R=E / i$, where $E$ represents the potential change and $i$ the applied current, the total resistance $(R)$ of the $\mathrm{Au} / \mathrm{MEH}-\mathrm{PPV} / \mathrm{Pb}^{2+}$-selective electrode is approximately $2.89 \mathrm{M} \Omega$.

With this method, one could also see the differences in the potential stability of different types of ISEs without performing traditional long-term stability study [28]. The two main characteristic, the potential jump and the slow potential drift at long times, can be clearly observed in Fig. 1, much less potential drift was observed with the MEH-PPV-based electrode as compared to that with the CDE. These results suggest that the potential stability can be dramatically improved by applying MEH-PPV as the solid contact between the Au substrate and the ion-selective membrane.

\subsection{Impedance measurements}

To further characterize the quality of MEH-PPV contact, electrochemical impedance spectroscopy (EIS) was performed. EIS data were recorded at open circuit potential with an ac amplitude of $100 \mathrm{mV}$ and a frequency range of $200 \mathrm{kHz}$ to $1 \mathrm{MHz}$ in deaerated $0.1 \mathrm{M} \mathrm{Pb}\left(\mathrm{NO}_{3}\right)_{2}$ solution. As shown in Fig. 2, the diameter of the high-frequency semicircle, which equals to the bulk membrane 


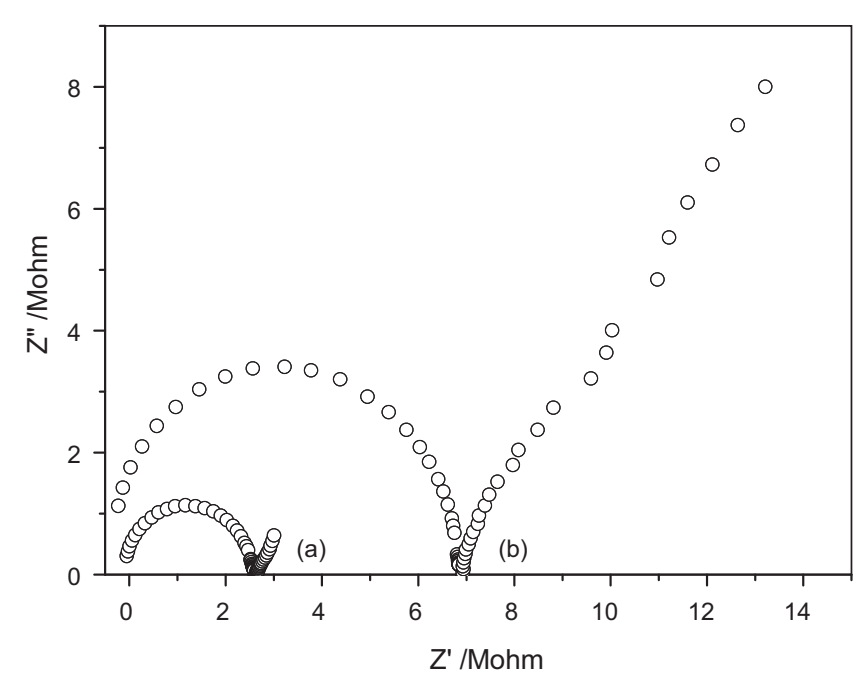

Fig. 2. EIS data for the $\mathrm{Pb}^{2+}$-selective electrodes: (a) $\mathrm{Au} / \mathrm{MEH}-\mathrm{PPV} / \mathrm{Pb}^{2+}$-selective membrane and (b) $\mathrm{Au} / \mathrm{Pb}^{2+}$-selective membrane (CDE).

resistance coupled with the contact resistance between the Au substrate and the PVC membrane, was decreased from 6.96 to $2.65 \mathrm{M} \Omega$, which is in good agreement with the chronopotentiometric result $(R=2.89 \mathrm{M} \Omega)$. The decrease in resistance values is due to that the charge transport across the interface is facilitated by the MEH-PPV inner contact [27]. Considering the solubility of MEH-PPV contact in THF, the ion-selective cocktail could dissolve MEH-PPV and a diffused intermixed layer is believed to form during the drying out of the PVC membrane. The formation of intermixed layer is beneficial for decreasing the impedance of electrode. Similar effects have been observed for PVC electrodes with polyaniline nanoparticle-based contact, and polyacrylate electrodes with POT contact $[17,29,30]$. The low-frequency part of the EIS for CDE showed a large semicircle arising from a small capacitance with a large charge-transfer resistance at the "blocked" interface Au/PVC membrane [28]. In the case of SC-ISE, the negligible of low-frequency semicircle indicates that the electronically and ionically conducting polymeric contact increases low-frequency capacitance and the ion-to-electron transduction occurs properly between the electronically conducting Au substrate and ionically conducting ion-selective membrane.

\subsection{Potentiometric performance characteristics}

Fig. 3 presents the potentiometric response of the electrodes with MEH-PPV inner contact. A linear range from $1 \times 10^{-3}$ to $2 \times 10^{-9} \mathrm{M}$ was observed with a Nernstern slope of $29.1 \pm 0.8 \mathrm{mV}$ decade $^{-1}\left(R^{2}=0.99\right)$. The detection limit calculated as the intersection of the two slope lines was $10^{-9.2} \mathrm{M}$. This low detection limit was achieved by conditioning the electrode in a solution containing both the primary ion and the interfering ion, sodium. The explanation for this effect has been well documented in Refs. [2,27]. The response time of the electrode was measured after successive immersion of the electrode in a series of $\mathrm{Pb}^{2+}$ solutions (Fig. 4). A response time of $10-15 \mathrm{~s}$ was required to achieve a steady potential within $0.5 \mathrm{mV}$ for measuring $\mathrm{Pb}^{2+}$ at concentrations ranging from $1.0 \times 10^{-3}$ to $1.0 \times 10^{-7} \mathrm{M}$, indicating that the absence of an inner solution favors the response time of the electrode $[8,19]$. At lower concentrations, however, the response time was longer and reached approximately $120 \mathrm{~s}$ for $\mathrm{Pb}^{2+}$ concentration below $1.0 \times 10^{-8} \mathrm{M}$. The selectivities were measured according to the separate solution method [31] after the electrodes were conditioned in a $10^{-3} \mathrm{M}$ solution of $\mathrm{Ca}\left(\mathrm{NO}_{3}\right)_{2}$ for $24 \mathrm{~h}$. The selectivity coefficients $\left(K_{P b, J}^{\text {pot }}\right)$ were calculated from the EMF values using Nicolsky-Eisenman equation, and the results are
Table 1

Selectivity coefficients, $\log K_{P b, J}^{\text {pot }}$, obtained with the MEH-PPV-based solid-contact electrode and with the coated-wire electrode.

\begin{tabular}{lrr}
\hline Ion $J$ & \multicolumn{1}{l}{ CDE } & \multicolumn{1}{c}{ SC-ISE } \\
\hline $\mathrm{Ca}^{2+}$ & $-15.7 \pm 0.3$ & $-16.5 \pm 0.2$ \\
$\mathrm{Na}^{+}$ & $-5.2 \pm 0.2$ & $-6.6 \pm 0.1$ \\
$\mathrm{H}^{+}$ & $-2.9 \pm 0.2$ & $-4.4 \pm 0.2$ \\
$\mathrm{Cu}^{2+}$ & $-3.3 \pm 0.1$ & $-4.6 \pm 0.1$ \\
$\mathrm{Cd}^{2+}$ & $-5.4 \pm 0.2$ & $-6.1 \pm 0.1$ \\
\hline
\end{tabular}

summarized in Table 1 . The $K_{P b, J}^{\mathrm{pot}}$ values obtained for the SC-ISE are comparable to the values reported for tailed inner solution $\mathrm{Pb}^{2+}$-selective electrode which incorporate the same ionophore in the membrane phase [32,33]. On the other hand, the SC-ISEs show somewhat better selectivity than CDEs. The potential drifts, and the ion leakage from the inner water layer formed between the $\mathrm{Au}$ substrate and ion-selective membrane may be the reason for the bias of the selectivity coefficients for the CDEs.

\subsection{Stability of the solid-contact $\mathrm{Pb}^{2+}$-ISES}

The stability of the proposed solid-contact ISEs was tested using the protocol developed by Pretsch and colleagues [22]. Potential measurements were initially done in $\mathrm{Pb}\left(\mathrm{NO}_{3}\right)_{2}$ solution, then in $\mathrm{Cu}\left(\mathrm{NO}_{3}\right)_{2}$, and again in $\mathrm{Pb}\left(\mathrm{NO}_{3}\right)_{2}$. Control experiments were con-

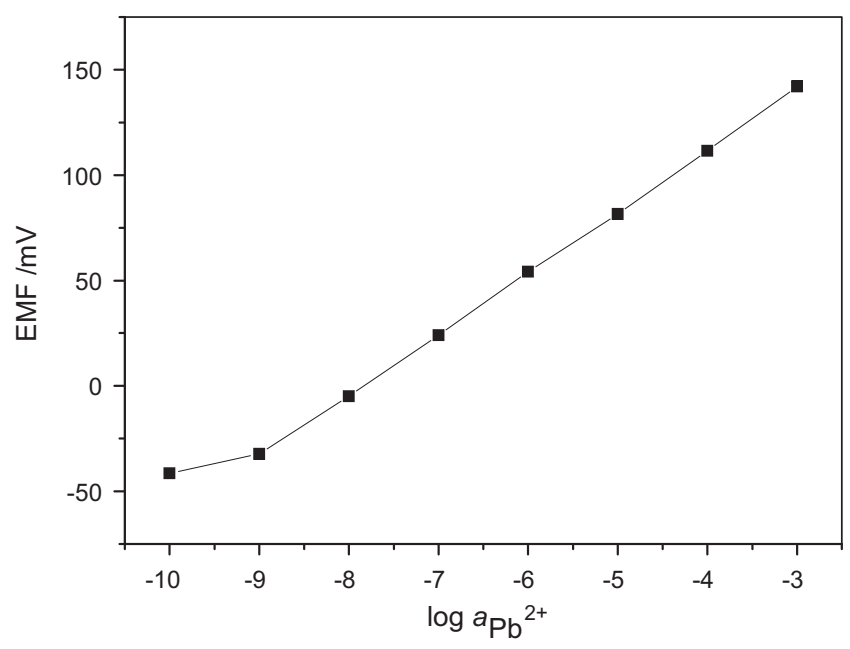

Fig. 3. Calibration curve of the solid-contact $\mathrm{Pb}^{2+}$-selective electrode.

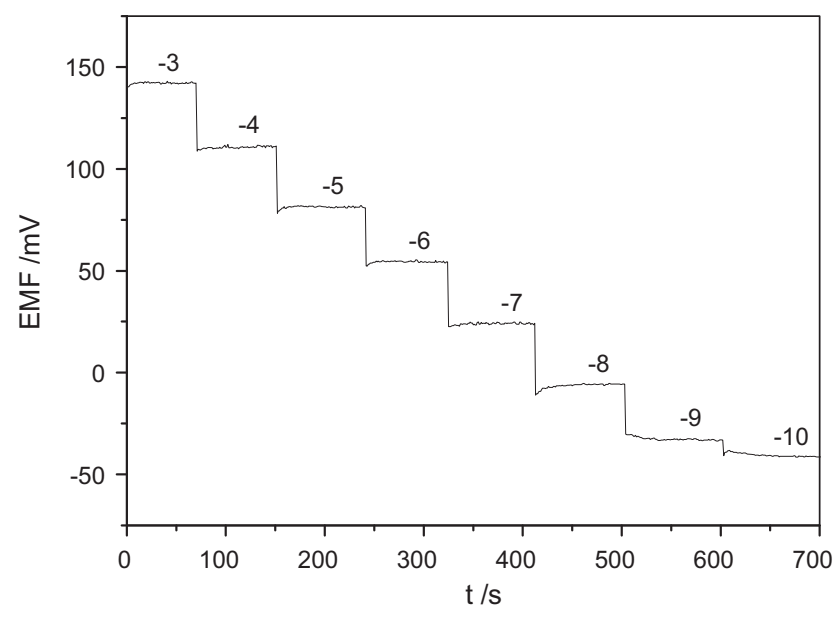

Fig. 4. Dynamic potentiometric response of the proposed electrode. 


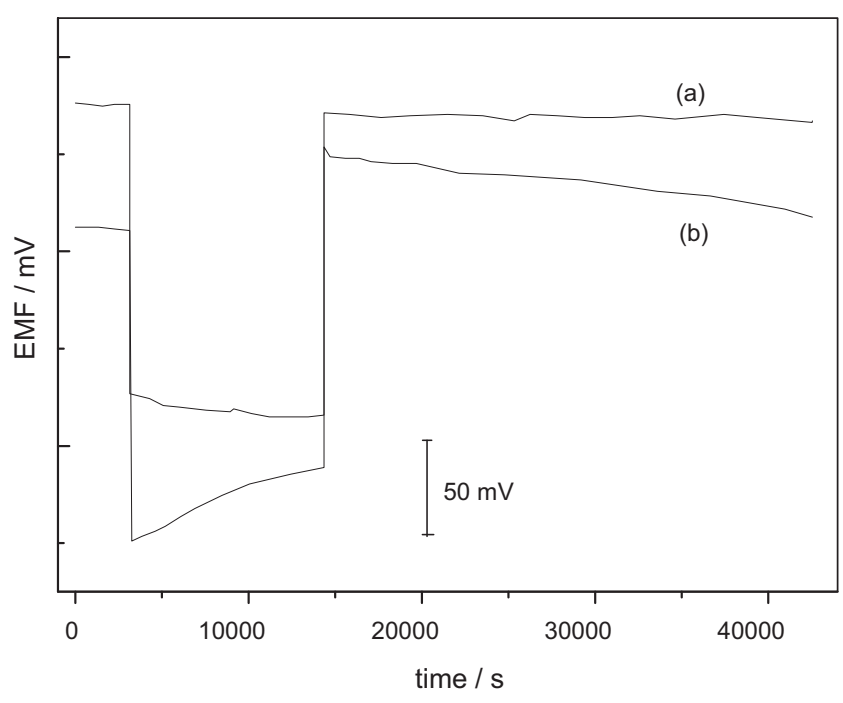

Fig. 5. Water layer test of (a) the solid-contact $\mathrm{Pb}^{2+}$-selective electrode and (b) the coated-wire electrode performed by successively measuring the EMF responses of $10^{-5} \mathrm{M} \mathrm{Pb}\left(\mathrm{NO}_{3}\right)_{2}, 10^{-3} \mathrm{M} \mathrm{Cu}\left(\mathrm{NO}_{3}\right)_{2}$ and again $10^{-5} \mathrm{M} \mathrm{Pb}\left(\mathrm{NO}_{3}\right)$.

Table 2

Determination of lead ion in real tap water sample $(n=3)$.

\begin{tabular}{lcc}
\hline Samples & SC-ISE $\left(\times 10^{-8} \mathrm{M}\right)$ & AAS $\left(\times 10^{-8} \mathrm{M}\right)$ \\
\hline 1 & $4.43 \pm 0.05$ & $4.26 \pm 0.03$ \\
2 & $4.96 \pm 0.06$ & $5.21 \pm 0.03$ \\
3 & $4.53 \pm 0.05$ & $4.78 \pm 0.02$ \\
\hline
\end{tabular}

ducted in parallel using the CDE. As shown in Fig. 5, the fabricated solid-contact ISE and control CDE show different response behaviors. Due to the ion exchange in the aqueous layer between the $\mathrm{Au}$ surface and the PVC membrane, potential drifts were observed for CDEs upon changing the analytes in the sample solution from the primary ion to the interfering ion and then again to the primary ion. On the contrary, no obvious potential drifts were observed for the SC-ISE during such procedure, indicating that undesirable water layer was eliminated in the sensor. These results could be attributed partly to the enhancing adhesion due to the formation of intermixed layer between the hydrophobic MEH-PPV contact and the ion-selective membrane addition.

\subsection{Applications}

The proposed SC-ISE was used to determine the concentration of $\mathrm{Pb}^{2+}$ in real tap water samples. The analysis was carried out by direct potentiometry using standard addition method. The results obtained were compared with those obtained by atomic absorption spectrometry (AAS) method as shown in Table 2 . The concentration of lead as determined by the direct potentiometric method was in good agreement with that obtained by the atomic absorption spectrometry (AAS) method.

\section{Conclusions}

We have prepared a solid-contact $\mathrm{Pb}^{2+}$-selective electrode based on MEH-PPV inner contact and PVC ion-selective membrane. Undesirable water layer can be effectively eliminated in this sen- sor. A Nernstian slope of $29.1 \pm 0.8 \mathrm{mV} \mathrm{decade}^{-1}\left(R^{2}=0.99\right)$ and a detection limit of $10^{-9.2} \mathrm{M}$ have been obtained. EIS test shows that MEH-PPV could effectively reduce the contact resistance and increase the capacitance. Results from chronopotentiometric measurements suggest a largely improved long-term potential stability. It can be concluded that using MEH-PPV as ion-to-electron transducer is a promising approach for the fabrication of solid-contact ISEs.

\section{Acknowledgments}

This work was financially supported by the Chinese Academy of Sciences (KZCX2-YW-JS208 and KZCX2-YW-410), the National 863 High Technology Project of the Ministry of Science and Technology of China (2007AA09Z103), the National Natural Science Foundation of China (40776058), the Science and Technology Bureau of Yantai (2009164), the Natural Science Foundation of Shandong Province (2008BS01022 and JQ200814) and the Taishan Scholar Program of Shandong Province.

\section{References}

[1] K. Chumbimuni-Torres, N. Rubinova, A. Radu, L. Kubota, E. Bakker, Anal. Chem. 78 (2006) 1318-1322.

[2] A. Michalska, Anal. Bioanal. Chem. 384 (2006) 391-406.

[3] L. Górski, A. Matusevich, M. Pietrzak, L. Wang, M.E. Meyerhoff, E. Malinowska, J. Solid State Electrochem. 13 (2009) 157-164.

[4] E.J. Parra, G.A. Crespo, J. Riu, A. Ruizb, F.X. Rius, Analyst 134 (2009) 19051910.

[5] A. Michalska, M. Wojciechowski, E. Bulska, K. Maksymiuk, Talanta 82 (2010) $151-157$.

[6] M. Fibbioli, K. Bandyopadhyay, S.G. Liu, L. Echegoyen, O. Enger, F. Diederich, D. Gingery, P. Bühlmann, H. Persson, U. Suter, E. Pretsch, Chem. Mater. 14 (2002) 1721-1729.

[7] M. Fouskaki, N. Chaniotakis, Anal. Chem. 77 (2005) 1780-1784.

[8] G. Crespo, S. Macho, F. Rius, Anal. Chem. 80 (2008) 1316-1322.

[9] R. Hernández, J. Riu, F.X. Rius, Analyst 135 (2010) 1979-1985.

[10] J. Zhu, Y. Qin, Y. Zhang, Electrochem. Commun. 11 (2009) 1684-1687.

[11] M.A. Fierke, C.-Z. Lai, P. Bühlmann, A. Stein, Anal. Chem. 82 (2010) 680-688

[12] J. Bobacka, A. Ivaska, A. Lewenstam, Chem. Rev. 108 (2008) 329-351.

[13] J. Sutter, E. Lindner, R. Gyurcsányi, E. Pretsch, Anal. Bioanal. Chem. 380 (2004) 7-14.

[14] A. Michalska, C. Appaih-Kusi, Y.H. Lee, S. Walkiewicz, E. Hall, Anal. Chem. 76 (2004) 2031-2039.

[15] R.E. Gyurcsányi, N. Rangisetty, S. Clifton, B.D. Pendley, E. Lindner, Talanta 63 (2004) 89-99.

[16] A. Michalska, M. Wojciechowski, W. Jędral, E. Bulska, K. Maksymiuk, J. Solid State Electrochem. 13 (2009) 99-106.

[17] T. Lindfors, J. Szücs, F. Sundfors, R. Gyurcsányi, Anal. Chem. 82 (2010) 9425-9432.

[18] A. Michalska, A. Konopka, M. Maj-Zurawska, Anal. Chem. 75 (2003) 141-144.

[19] J. Sutter, A. Radu, S. Peper, E. Bakker, E. Pretsch, Anal. Chim. Acta 523 (2004) 53-59.

[20] P.C. Hauser, D.W.L. Chiang, G.A. Wright, Anal. Chim. Acta 302 (1995) 241-248

[21] E. Lindner, R. Gyurcsányi, J. Solid State Electrochem. 13 (2009) 51-68.

[22] M. Fibbioli, W.E. Morf, M. Badertscher, N. de Rooij, E. Pretsch, Electroanalysis 12 (2000) 1286-1292.

[23] J. Veder, R. Marco, G. Clarke, R. Chester, A. Nelson, K. Prince, E. Pretsch, E. Bakker Anal. Chem. 80 (2008) 6731-6740.

[24] Y. Qin, S. Peper, E. Bakker, Electroanalysis 14 (2002) 1375-1381.

[25] L.Y. Heng, K. Tóth, E.A.H. Hall, Talanta 63 (2004) 73-87.

[26] S.M. Zhang, D.G. Ma, J. Phys. D: Appl. Phys. 41 (2008) 045102.

[27] A. Konopka, T. Sokalski, A. Michalska, A. Lewenstam, M. Maj-Zurawska, Anal. Chem. 76 (2008) 6410-6418.

[28] J. Bobacka, Anal. Chem. 71 (1999) 4932-4937.

[29] T. Lindfors, H. Aarnio, A. Ivaska, Anal. Chem. 79 (2007) 8571-8577.

[30] E. Jaworska, A. Kisiel, K. Maksymiuk, A. Michalska, Anal. Chem. 83 (2011) 438-445.

[31] E. Bakker, E. Pretsch, P. Bühlmann, Anal. Chem. 72 (2000) 1127-1133.

[32] A. Ceresa, E. Pretsch, Anal. Chim. Acta 395 (1999) 41-52.

[33] A. Ceresa, E. Bakker, B. Hattendorf, D. Günther, E. Pretsch, Anal. Chem. 73 (2001) 343-351. 